\title{
Study of Nano Hydroxyapatite/ Poly(Lactic Acid)-Polycaprolactone Nanofiber Composite Scaffolds
}

\author{
Guojie Xu \\ Key Laboratory of Polymer Materials, College of \\ Chemistry And Chemical Engineering \\ Fujian Normal University \\ Fuzhou, China \\ e-mail: xuguojie-0935@163.com
}

Fei Luo

Key Laboratory of Polymer Materials, College of Chemistry And Chemical Engineering

Fujian Normal University

Fuzhou, China

e-mail: 781069499@qq.com

Yan Liu

Key Laboratory of Polymer Materials, College of Chemistry And Chemical Engineering

Fujian Normal University

Fuzhou, China

e-mail: 522975901@qq.com

\author{
Shunyu Chen \\ Key Laboratory of Polymer Materials, College of \\ Chemistry And Chemical Engineering \\ Fujian Normal University \\ Fuzhou, China \\ e-mail: 1329431480@qq.com \\ Xiufeng Xiao* \\ Key Laboratory of Polymer Materials, College of \\ Chemistry And Chemical Engineering \\ Fujian Normal University \\ Fuzhou, China \\ e-mail: xfxiao@fjnu.edu.cn
}

\begin{abstract}
At present, tissue engineering scaffolds in the process of clinical medicine plays an irreplaceable important role. Based on the in-situ precipitation combined with frozen extraction, good n-HA dispersion and three-dimensional (3D) structure of n-HA/PLLA-PCL composite nanofibrous scaffolds were prepared. The effects of the proportion of polymer, gel temperature and the amount of calcium phosphate solution on the morphology of nanofibrous scaffolds were investigated. From the experimental results,it can be concluded that the scaffolds' morphology have changed while the proportions of the polymer are different, and with more PCL, the fiber diameter increases. At low gel temperature $\left(-10^{\circ} \mathrm{C}\right.$ or lower), n-HA/PLLA-PCL composite scaffolds could be able to get relatively uniform nano fiber network structure, while at high gel temperature $\left(0^{\circ} \mathrm{C}\right.$ or higher), nanofibers tend to flake growth, support structure is more compact. Also, with the adding of $\left(\mathrm{NH}_{4}\right)_{2} \mathrm{HPO}_{4}$ solution, nanometer fiber diameter increases, however, the degree of uniformity decreases.
\end{abstract}

Keywords- hydroxyapatite composite scaffold; nanofibers; thermal induced phase separation technique; in-situ precipitation; frozen extraction

\section{INTRODUCTION}

The strategy of bone tissue engineering is to prepare the scaffolds with high permeability of three-dimensional (3D) structure. These scaffolds mainly induce the formation of new tissue and provide a brief environment for cells' adsorption, migration, breeding and differentiation. Nanofibrous materials, for the conformity to natural bone natural extracelluar matrix(ECM) structure, conducive to simulate cell survival environment, and cell adhesion, proliferation, differentiation and function expression because of the high specific surface area. Therefore, materials with nanoscale structure have a very attractive prospect in bone tissue engineering.

Thermal induced phase separation technique (TIPS) ${ }^{[1]}$ which use simple equipment and easy operation, can control the formation of complex three-dimensional structure by means of experimental parameters. The structure of scaffolds which is similar to natural extracelluar matrix has more advantages for cell adhesion, growth, reproduction and functionalization. Thus, TIPS has become an effective method to fabricate scaffolds with 3D structure. Hydroxyapatite (HA), poly(lactic acid)(PLLA) ${ }^{[2]}$, polycaprolactone $(\mathrm{PCL})^{[3]}$, poly(glutamic acid)(PGA) ${ }^{[4]}$ and their copolymer ${ }^{[5]}$, are widely used for the preparation of scaffolds. Combining with the advantage of HA and polymer, people pay more attention about this kind of composites. The dispersion of HA in polymer matrix is the critical factor about material properties, but it hasn't get a satisfactory solution. Most researchers use mechanical ${ }^{[6,7]}$ or ultrasonic stirring ${ }^{[8]}$ to improve the dispersion of HA, however, the effect is temporarily, and do not have the effect during the process of materials combination. 
Based on the in-situ precipitation combined with frozen extraction, good n-HA dispersion and threedimensional (3D) structure of n-HA/PLLA-PCL composite nanofibrous scaffolds were prepared. The effects of the proportion of polymer, gel temperature, the amount of calcium phosphate solution and porogen on the morphology of nanofibrous scaffolds were investigated.

\section{EXPERIMENT SECTION}

\section{A. The proportion of PLLA and PCL}

PLLA and PCL were purchased respectively from Jiangsu Yuli Co Ltd. and Daicel Chemical Industries, Ltd. $\mathrm{Ca}\left(\mathrm{NO}_{3}\right)_{2} \cdot 4 \mathrm{H}_{2} \mathrm{O}(\mathrm{AR}),\left(\mathrm{NH}_{4}\right)_{3} \mathrm{PO}_{4} \cdot 3 \mathrm{H}_{2} \mathrm{O}(\mathrm{CP})$ and 1,4 dioxane were obtained from China National Pharmaceutical Shanghai Chemical Reagent Corporation. Double-distilled water made in lab was used in all process.

\section{B. Preparation of scaffolds.}

PLLA and PCL (PLLA: PCL = 70:30) was dissolved in the 1, 4 - dioxane/water mixed solvent $(\mathrm{W} / \mathrm{W}=90 / 10)$ system to make a homogeneous polymer solution under $60^{\circ} \mathrm{C}$. After that, in turn, both $\mathrm{Ca}\left(\mathrm{NO}_{3}\right)_{2}$ solution $(2.0$ $\left.\mathrm{mol} \cdot \mathrm{L}^{-1}\right)$ and $\left(\mathrm{NH}_{4}\right)_{2} \mathrm{HPO}_{4}\left(1.2 \mathrm{~mol} \cdot \mathrm{L}^{-1}\right)$ was added into the polymer solution with the proportion of $\mathrm{Ca}$ and $\mathrm{P}$ about 1.67. Adjust the solution $\mathrm{PH}$ above 10 and continue stirring for 5 minutes. Weight out $6 \mathrm{~g}$ in $25 \mathrm{ml}$ small beaker, first place the beaker into $-15^{\circ} \mathrm{C}$ to make a gelatinization for about $2 \mathrm{~h}$, and then the beaker was placed in $4^{\circ} \mathrm{C}$ biochemical incubator with secondary distilled water to extract $72 \mathrm{~h}$ (every $8 \mathrm{~h}$ to replace an extraction liquid). In the end, the scaffold was obtained after drying 3 days in freeze drier at $-54^{\circ} \mathrm{C}$.

In the case of other conditions unchanged, we explored the influence of the following conditions respectively: (1) The gel temperature $\left(5^{\circ} \mathrm{C}, 0^{\circ} \mathrm{C}, 10^{\circ} \mathrm{C}\right.$, $\left.15^{\circ} \mathrm{C}, 20^{\circ} \mathrm{C}\right)$; (2) The proportion of PLLA and PCL (50:50, $60: 40,70: 30,80: 20,90: 10)$; (3) The amount of $\left(\mathrm{NH}_{4}\right)_{2} \mathrm{HPO}_{4}$ solution $(0.2 \mathrm{ml}, 0.4 \mathrm{ml}, 0.6 \mathrm{ml}, 0.8 \mathrm{ml}, 1.0$ $\mathrm{ml})$.

\section{RESULTS AND DISCUSSION}

\section{A. The proportion of PLLA and PCL}

Fig .1 displays the SEM of n-HA/PLLA-PCL composite scaffold with different proportion of PLLA and PCL. As is shown in Fig .1 (a, b, c, d, e), the in-situ precipitation combined with frozen extraction can get high porosity n-HA/PLLA-PCL nanofiber composite scaffolds. When the concentration of PCL was below $50 \%$, all samples had nanofibrous structure, and increasing of the proportion of PCL, the diameter of nanofiber would also increase. We supposed that those two polymers, PLLA and PCL, had different glass transition temperature and crystallization behavior. While the two mixed together, they would influence each other, thus leaded to the difference of nanofiber. When the proportion of PCL increased to $80 \%$, it could be thought as polymer matrix was given priority to PCL, shown in Fig .1 (f, g), it presented as a ball with three-dimensional spherical nanofiber network, which was totally different from the structure of PLLA. However, as the proportion of PCL was beyond $50 \%$, the mechanical properties of the scaffolds turned to poorer, easier to cause collapse, thus there was no discussion any more.

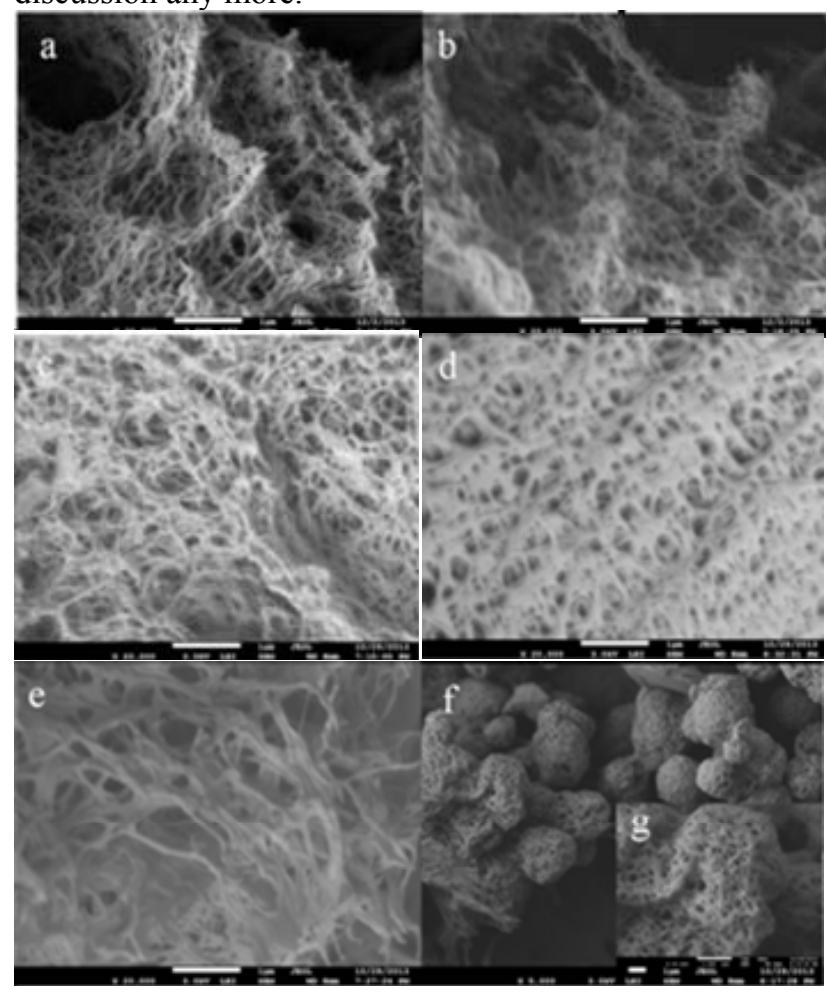

Figure 1. Scanning electron micrographs of n-HA/PLLA-PCL scaffolds prepared in different mass ratio of (PLLA:PCL). (a) 90:10, (b) $80: 20$, (c) $70: 30$, (d) $60: 40$, (e) $50: 50$, (f) $20: 80$

\section{B. The amount of $\left(\mathrm{NH}_{4}\right)_{2} \mathrm{HPO}_{4}$ solution}

Fig .2 shows the scaffolds with different adding volume of $\left(\mathrm{NH}_{4}\right)_{2} \mathrm{HPO}_{4}$ solution under $-15^{\circ} \mathrm{C}$ gel temperature. Shown in Fig .2, the diameter of nanofibers would be affected with the addition of $\left(\mathrm{NH}_{4}\right)_{2} \mathrm{HPO}_{4}$ solution, with the adding of $\left(\mathrm{NH}_{4}\right)_{2} \mathrm{HPO}_{4}$ solution, nanometer fiber diameter increased, however, the degree of uniformity decreased. This may be due to the increase of $\left(\mathrm{NH}_{4}\right)_{2} \mathrm{HPO}_{4}$ solution which was equivalent to the adding of nonsolvent reduced the solubility of the polymer. The diluting effects and viscosity reduction of the co-solvent system could lead to poor polymer phase form larger droplet area ${ }^{[9,10]}$, thus increased scaffolds' nonuniformity. In addition, increasing the proportion of nonsolvent, could increase the gel point, which would reduce the energy of coarsening effect in the early stage of phase separation, resulting in pore size and the fiber diameter increased. That is shown in Fig .2. And as we can see, among the discussing volume range, namely within $1.0 \mathrm{ml}$, samples remained nanometer fiber network structure, which played the important role for bone cells adhesion, proliferation and growth, metabolism and nutrients' transportation. 


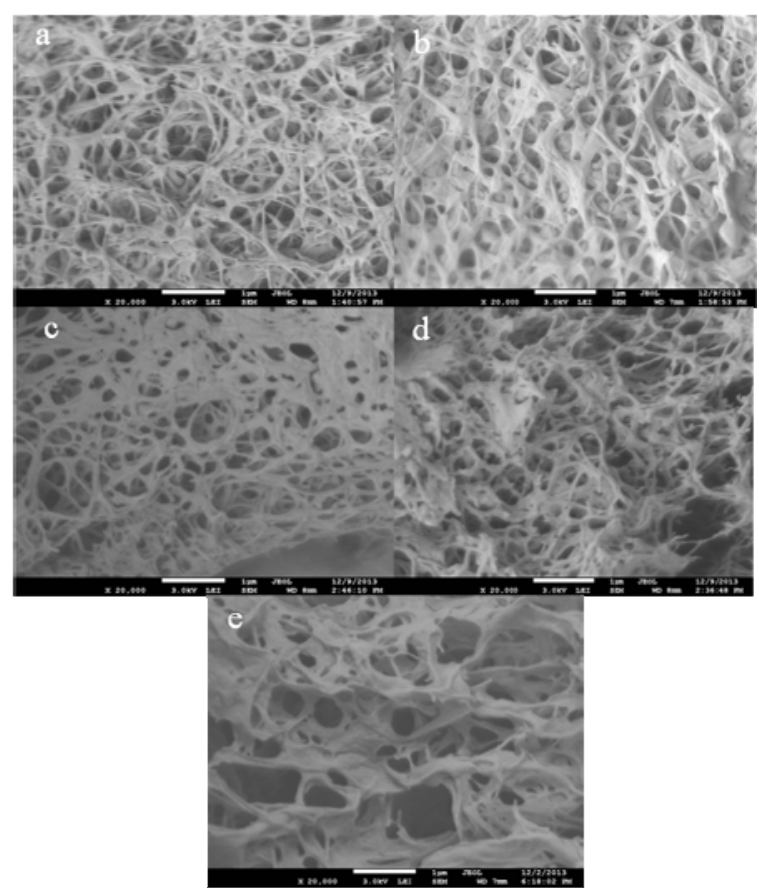

Figure 2. SEM of n-HA/PLLA-PCL composite scaffolds prepared with different volume of $\left(\mathrm{NH}_{4}\right)_{2} \mathrm{HPO}_{4}$ solution. (a) $0.2 \mathrm{ml}$, (b) $0.4 \mathrm{ml}$,

(c) $0.6 \mathrm{ml}$, (d) $0.8 \mathrm{ml}$, (e) $1.0 \mathrm{ml}$

\section{The gel temperature}

Using in situ method combined with the frozen extraction, $7 \%$ PLLA-PCL (70/30) added both $0.6 \mathrm{~mL}$ $\mathrm{Ca}\left(\mathrm{NO}_{3}\right)_{2}$ solution concentration $\left(2.0 \mathrm{~mol} \cdot \mathrm{L}^{-1}\right)$ and $\left(\mathrm{NH}_{4}\right)_{2} \mathrm{HPO}_{4}\left(1.2 \mathrm{~mol} \cdot \mathrm{L}^{-1}\right)$ solution into the polymer

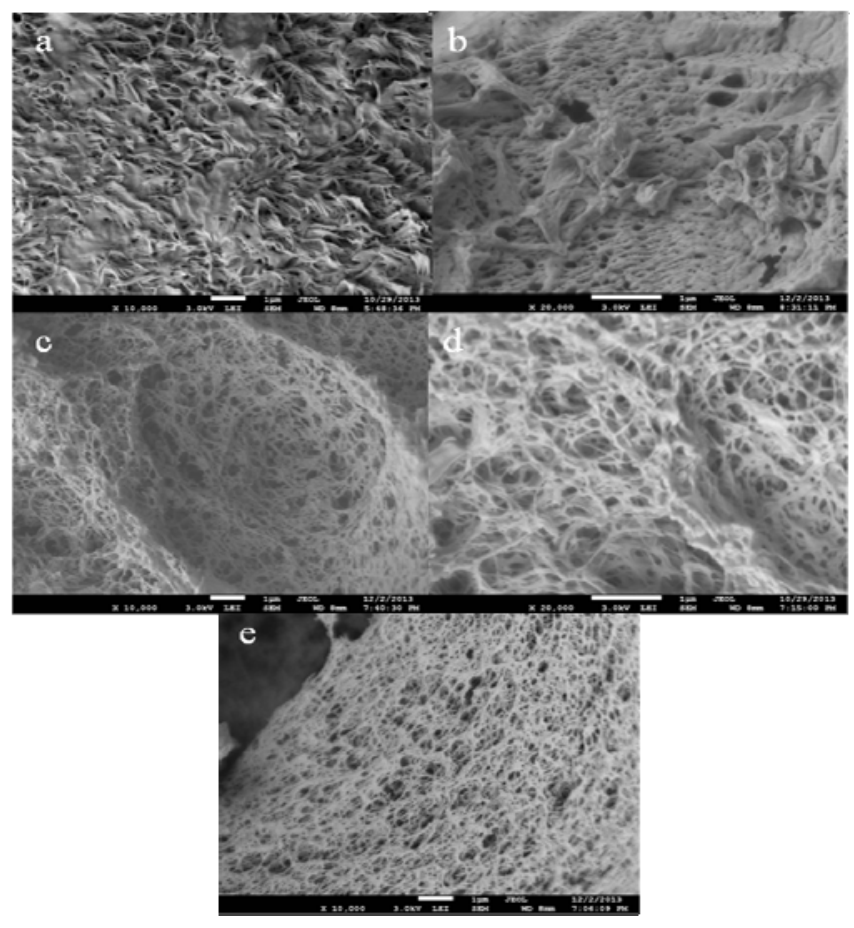

Figure 3. SEM of n-HA/PLLA-PCL composite scaffolds prepared in situ method system at different gelation temperature. (a) $5{ }^{\circ} \mathrm{C}$ (b) $0{ }^{\circ} \mathrm{C}$ (c) $-10{ }^{\circ} \mathrm{C}$ (d) $-15^{\circ} \mathrm{C}$ (e) $-20^{\circ} \mathrm{C}$ solution. After different gel temperature preparation, their SEM figures are shown in Fig .3. As we can see, nanofibers appeared while the gel temperature fell sharply, besides fiber diameter decreased as the temperature continued falling. Phase separation of polymer solution can be seen as a process of self-assembly, replace the small molecule self-assembly, macromolecule from the initial homogeneous phase gathered to form a new phase much more easily ${ }^{[11]}$. Thermal and nonsolvent induced phase separation made polymer microcrystalline, therefore, gelation is quite essential to form a fiber network structure phase.

\section{CONCLUSION}

The three dimensional nano fiber network structure of n-HA/PLLA-PCL composite scaffolds were successfully fabricated and the hydroxyapatite was well dispersed in scaffolds. The effects of the proportion of polymer, gel temperature and the amount of calcium phosphate solution on the morphology of nanofibrous scaffolds were investigated. Results indicated that the scaffolds' morphology had changed while the proportions of the polymer were different, and with more PCL, the fiber diameter increased. At lower temperatures $\left(-10^{\circ} \mathrm{C}\right.$ or less), n-HA/PLLA-PCL composite scaffolds could be able to get relatively uniform nano fiber network structure, while at high gel temperature $\left(0^{\circ} \mathrm{C}\right.$ or higher $)$, nanofibers tended to flake growth, support structure turned more compact.

\section{ACKNOWLEDGMENT}

This work was financially supported by National Nature Science Foundation of China (30970887), the Science Research Foundation of Ministry of Health (WKJ 2008-2-037), Fujian Province Nature Science Foundation (2011J06019, 2012J01194).

\section{REFERENCES}

[1] Ma, P.X. Biomimetic materials for tissue engineering [J]. Advanced Drug Delivery Reviews, 2008, 60(2): 184-198.

[2] Anand S. Badamia, M.R.K., M. Shane Thompsonb, Judy S Riffle,Aaron S Goldstein. Effect of fiber diameter on spreading, proliferation, and differentiation of osteoblastic cells on electrospun poly(lactic acid) substrates [J]. Biomaterials, 2006, 27(4): 596-606.

[3] Su A. Park, Jung Bok Lee, Yang Eun Kim, et al. Fabrication of biomimetic PCL scaffold using rapid prototyping for bone tissue engineering [J]. Macromolecular Research, 2014, 22(8): 882-887.

[4] Feng Jun, Gao Weixia, Gu Yanyan, et al. Functions of polygamma-glutamic acid ( $\gamma$-PGA) degradation genes in $\gamma$-PGA synthesis and cell morphology maintenance[J]. Applied Microbiology and Biotechnology, 2014. 98(14): 6397-6407..

[5] Helena N Chia, Benjamin M Wu. High-resolution direct 3D printed PLGA scaffolds: print and shrink [J]. Biofabrication, 2014, 7(1): 015002 .

[6] Kasuga T, Maeda H, Kato K, et al. Preparation of poly(lactic acid) composites containing calcium carbonate (vaterite) [J]. Biomaterials, 2003, 24(19): 3247-3253.

[7] Sada E, Kumazawa H, Murakami Y. Hydrothermal synthesis of crystalline hydroxyapatite ultrafine particles [J]. Chemical Engineering Communications, 1991, 103(1): 57-64.

[8] Y. Fang, D.K. Agrawal, D.M. Roy, et al. Ultrasonically accelerated synthesis of hydroxyapatite [J]. Journal of Materials Research, 1992, 7(08): 2294-2298. 
[9] Gen-Liang Ji, Bao-Ku Zhu, Zhen-Yu Cui, et al. PVDF porous matrix with controlled microstructure prepared by TIPS process as polymer electrolyte for lithium ion battery [J]. Polymer, 2007, 48(21): 6415-6425.

[10] Lloyd DR, Kim SS, Kinzer KE. Microporous membrane formation via thermally-induced phase separation. II. Liquid-liquid phase separation [J]. Journal of Membrane Science, 1991, 64(1): 1-11.
[11] Nam YS, Park TG. Biodegradable polymeric microcellular foams by modified thermally induced phase separation method [J]. Biomaterials, 1999, 20(19): 1783-1790. 